\title{
ВОЗМОЖНОСТИ РАЗВИТИЯ ПРОГРАММ ИМПОРТОЗАМЕЩЕНИЯ ЧЕРЕЗ РЕАЛИЗАЦИЮ СТРАТЕГИЙ ТЕРРИТОРИАЛЬНОГО МАРКЕТИНГА "
}

\author{
(c) 2018 Черешнюк Александр Сергеевич \\ Омский государственный технический университет \\ 644050, Омск, пр. Мира, д. 11
}

В статье рассматривается подход к развитию программы импортозамещения в промышленности через стратегии инструменты территориального маркетинга. Подробно описываются содержание и особенности четырех базовых стратегий территориального маркетинга: маркетинг имиджа; маркетинг привлекательности; маркетинг инфраструктуры; маркетинг людей. Указанные стратегии могут быть приоритетными для разных территорий в зависимости от двух параметров. Первый - это характеристики, особенности и конкурентные преимущества самой территории (как территориально- и исторически обусловленные, так и созданные усилиями власти и жителей). Второй параметр - это приоритеты в развитии экономики и промышленности государства в конкретный момент времени (например, развитие импортозамещения в промышленности). Автор предлагает использовать данный подход для промышленных регионов Сибирского федерального округа в использовании данных стратегий для включения региональных проектов в программу импортозамещения.

Ключевые слова: промышленность, импортозамещение, Сибирский федеральный округ, стратегии маркетинга территорий.

Развитие программы импортозамещения в Российской Федерации в последние годы значительно замедлилось, поскольку принятые на первых этапах программы меры, ориентированные на развитие внутреннего производства товаров и технологий, имеющих критическое значение для государства, в значительной мере исполнены. Сейчас и на последующих этапах к разработке программ, по мнению автора, стоит подходить более точечно, используя как основу для развития таких программ приоритеты, обозначенные государством и изучая особенности отдельных территорий страны, имеющих уникальное сочетание характеристик и ресурсов для развития производства конкретных товаров или технологий.

Для рассмотрения возможностей такого подхода к развитию государственной программы по развитию внутреннего производства, ориентированного на замену импортных товаров и технологий, можно использовать за основу подходы из территориального маркетинга. Поскольку маркетинг территорий как раз и подразумевает максимальное использование особенностей территории и ресурсов для развития потенциала территории (например, региона) через развитие производств, услуг и технологий, опирающихся на эти ресурсы или иные особенности территории.
Для начала стоит рассмотреть имеющиеся стратеги территориального маркетинга и их особенности, а затем применить данный подход к возможному решению проблемы развития импортозамещения в регионах, входящих в Сибирский ФО.

На первый взгляд кажется, что маркетинговая стратегия территории не имеет особого отношения к федеральным программам или развитию предприятий на местах. Но любому экономисту известно, что при выборе места или региона для реализации серьезного проекта, любой инвестор в той или иной степени будет ориентироваться на рейтинги региона (инвестиционные и др.). Аналогично как мы, будучи потребителями, выбираем товары, ориентируясь на место его происхождения. Такая информация, опирающаяся на известную информацию об этом месте, является ключевым фактором принятия решения о покупке. В последнее время многие территории также занимаются своим брендингом, чтобы привлекать инвесторов и других субъектов, которым потенциально может быть интересна данная территория для осуществления инвестиционной, предпринимательской или социальной деятельности.

Отсюда становится ясно, что долгосрочный успех федеральных программ развития сильно

* Исследование выполнено при финансовой поддержки РФФИ, проект № 17-32-00037 
зависит от того, насколько осознанно и активно каждая территория страны разрабатывает и реализует свою маркетинговую стратегию, какова направленность и содержание этой стратегии.

Традиционно выделяют четыре группы стратегий территориального маркетинга, нацеленных на привлечение резидентов, притяжение экономических субъектов или на экспорт региональных продуктов:

1) Маркетинг имиджа;

2) Маркетинг привлекательности;

3) Маркетинг инфраструктуры;

4) Маркетинг людей, персонала [1, с.31].

Далее рассмотрим подробнее перечисленные стратегии.

Основная цель маркетинга имиджа - создание, развитие и распространение положительного образа и общественного признания территории [2]. Данная стратегия обычно не требует специального формирования факторов привлекательности территории, а скорее отталкивается от тех реальных преимущество и особенностей, которыми эта территория обладает. Усилия здесь направлены на улучшении коммуникаций с различными стейкхолдерами территории для повышения узнаваемости и интереса с целью привлечения на территорию определенных проектов развития. В рамках этой стратегии часто проводятся мероприятия, повышающие открытость территории для различного рода контактов, событий, людей.

По сравнению с другими, эта стратегия считается относительно недорогой.

Ф. Котлер дает следующее определение понятию имидж места: «это решающий фактор, определяющий то, как жители и деловые круги будут реагировать на данное место» [3, с.204].

Важнейшей составляющей имиджа территории является совокупность конкурентных преимуществ и недостатков. Они обусловливаются особенностями отраслевой специализации региона, наличием промышленного и экспортного потенциала, территориальной удаленностью и транспортной освоенностью, интеллектуальным и инновационным т.д.

Конкурентные преимущества и недостатки территории существенным образом отражаются на ее инвестиционной привлекательности [4]. По мнению Черной И.П., основу инвестиционной привлекательности составляют три в значительной степени самостоятельные характеристики: инвестиционный потенциал, инвестиционный риск и инвестиционное законодательство [5, с.37]. Их оценка позволяет определить инвестиционный рейтинг регионов России.

Использование необходимых инструментов территориального маркетинга имиджа должно сыграть особую роль в позиционировании территории, определении стратегии деятельности органов власти и населения для развития ее преимуществ и уменьшения конкурентных недостатков. Это тем более актуально, что создание образа региона - долгосрочная работа, она не только способствует развитию экономики, но и создает благоприятный фон для повышения качества жизни населения, улучшая существующий психологический микроклимат и снимая социальную напряженность [6].

Эта стратегия в значительной степени зависит от действий региональных и местных органов власти, которые, демонстрируя определенные политические способности и амбиции, могут реализовать «иконный маркетинг», связанный с образом конкретных лиц.

И.П. Черная в своей статье приводит результаты эмпирических исследований, которые показывают, что существуют следующие направления маркетинговой политики в сфере улучшения образа территории: «реализация ее трех основных функций - места жительства, места отдыха и места хозяйствования; улучшение управления и инфраструктуры территории; повышение конкурентоспособности расположенных в регионе предприятий» [5].

Для инвесторов, которые рассматривают разные регионы как площадки для реализации своих проектов (в том числе, ориентированных на импортозамещение), наиболее важной в этой связи является группа «внешних стейкхолдеров», которым необходимо различными способами попытаться демонстрировать возможности проверки и значимости конкурентных преимуществ конкретного региона.

Описанные выше цели являются сложными и связаны со многими другими факторами. Например, в условиях ограниченности финансовых ресурсов, особое значение приобретает коммуникационная активность правительства или иных органов государственной власти, поскольку формирование имиджа - процесс небыстрой и довольно сложный.

Как следует из практики, при формировании определенного имиджа региона из многочисленных источников информации и фактов, нуж- 
но формировать и освещать факты и события, которые наиболее интересны потенциальным партнерам. Это может быть динамика социально-экономических процессов; доступность и стоимость рабочей силы; технологические преимущества; инвестиционные условия; личность руководителей региона.

Говоря об этой стратегии, также нужно учитывать, что при работе с непривлекательным имиджем необходимо правильно четко понимать поставленные цели-ориентиры развития региона и правильно подбирать инструменты их реализации и продвижения. Так А.Н. Ситникова считает, что многие территории традиционно имеют положительный имидж, который необходимо только поддерживать и укреплять. Другие территории обладают противоречивым или смешанным имиджем, и им необходимо пересматривать стратегии своей работы и менять постепенно представления о данном регионе. Есть территории со слабым имиджем, когда преимущества территории ярко не выражены или предлагаются не тем ключевым стейкхолдерам. В этом случаем необходимо активное продвижение и целенаправленное создание нужного имиджа. Наконец, территории с явно негативным имиджем нуждаются в создании принципиально нового образа, направленного на нивелирование стереотипов об их недостатках [2].

Маркетинг привлекательности включает инструменты, направленные на повышение притягательности территории для людей определенных групп, возрастов, что в основном делают относительно потенциальных «туристов». Чаще всего в этом случае территория позиционируется через различные достопримечательности, уникальные историко-архитектурные и природные объекты, культуру и традиции территории, благоприятный климат и экологическую обстановку. Отдельно в рамках такой стратегии проводиться подготовка территории к проведению особых мероприятий (Чемпионаты мира, Олимпийские игры.

Привлекательность территорий для людей обеспечивается путем благоустройства набережных, создания пешеходных маршрутов, музейных экспозиций, исторических парков и реконструкций, создания архитектурных объектов.

В настоящее время все чаще наряду с другими конкурентными преимуществами приобретают такие, как качество и доступность образования на территории, уровень жизни, ин- фраструктура транспорта и связи, безопасность для людей и осуществления бизнеса.

Для усиления привлекательности своего региона, органы местной власти должны следует стратегию маркетинга привлекательности данной территории через популяризацию особых условий и отношений, демонстрирующих преимущества по сравнению с другими.

Надо заметить, что в отличие от маркетинга имиджа, маркетинг привлекательности служит основой для создания и развития конкурентных преимуществ территории. Маркетинг имиджа же пропагандирует уже созданные преимущества территории.

Маркетинг инфраструктуры подразумевает работу по обеспечению эффективного функционирования и развития территории в целом. Данная стратегия предусматривает создание имиджа территории как места, где созданы наиболее благоприятные условия для повседневной жизни, работы и развития, с опережающем развитием инфраструктуры жилых районов и промышленности, коммуникаций, транспорта и других параметров.

Для управления долгосрочным интересом к территории, есть только 2 типа аргументов, которыми можно управлять:

1. аргументы функционирования;

2. аргументы развития [1, с.37].

К аргументам функционирования относятся: механизмы обеспечения безопасности личности и общественного порядка; состояние и эксплуатация жилищного, дорожного и транспортного фонда; ресурсоснабжение и пр. Для бизнеса это любые налоговые преференции, возможности льготного приобретения или аренды земли и доступность качественной инфраструктуры и Т.П.

Среди направлений перспективности развития региона в первую очередь могут быть названы: возможность развития новых и перепрофилирования производств; современное состояние инфраструктуры и коммуникаций; состояние и перспективы рынка труда; уровень доходов населения; динамика инвестиций; качество и доступность образования.

Стратегии маркетинга населения, персонала различаются в зависимости от территории и ее потребностей в привлечении конкретных групп населения. Например, территории с высокой безработицей и неквалифицированной рабочей силой необходимо ориентироваться на 
привлечение предпринимателей и бизнеса для открытия новых проектов и создания более квалифицированных рабочих мест. Если, наоборот, занятых не хватает, а рабочих мест в избытке, то территории, для привлечений необходимых групп людей, нужно демонстрировать хорошие возможности для проживания и возможности развития, высокую заработную плату, возможность выбора профессии и т.п.
Следует отметить, что сосредоточение усилий на реализации только одной стратегии для большинства региона малоэффективно и недальновидно. Гораздо интереснее вести речь об формировании некоторой последовательности (сменяемости) маркетинговых стратегий, в том числе с учетом долгосрочных планов и перспектив развития территории и финансовых возможностях.

\section{Библиографический список}

1. Панкрухин А.П. Маркетинг территорий: Учебное пособие. Москва, Издательство РАГС, 2002.- С. 31

2. Ситникова А.О. Концепция территориального маркетинга Алтайского края [Электронный ресурс] - Режим доступа: http://www.pandia.ru/text/77/30/98289.php

3. отлер Ф.- Маркетинг мест. - СПб: Стокгольмская школа экономики в Санкт-Петербурге, 2011.- С. 204.

4. Зиннуров И.Ф., Ситнова И.А. Региональное развитие: Инструменты территориального маркетинга как фактор повышения конкурентоустойчивости региона [Электронный ресурс]: Региональная экономика и управление: электронный научный журнал. - 2011. - № 1.- Режим доступа: http://region.mcnip.ru/modules. php?name=News \&file $=$ article $\&$ sid $=148$

5. Черная И.П. Маркетинг имиджа как стратегическое направление территориального маркетинга // Маркетинг в России и за рубежом. - 2002.- № 4.- С. 37.

6. Управление реализацией стратегий развития муниципальных образований. Выпуск 52 - М.: МОНФ, 2004.C.260-271. 